
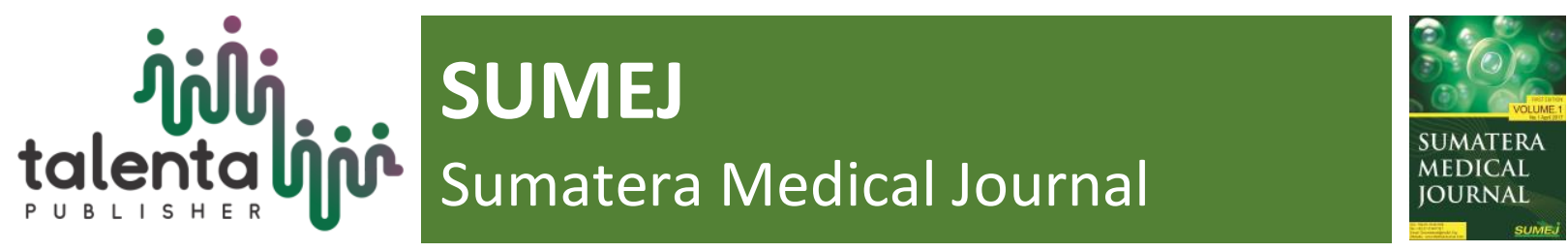

\title{
Adherence to European Society of Cardiology Heart Failure Treatment Guideline in Haji Adam Malik General Hospital Medan
}

\author{
A. Sitepu ${ }^{1^{*}}$, A. P. Wirtanto ${ }^{2}$ \\ ${ }^{1,2}$ Department of Cardiology and Vascular Medicine, Faculty of Medicine, University of Sumatera Utara, \\ Medan, Indonesia
}

\begin{abstract}
Background. Heart failure is a public health problem and the main cause of morbidity and mortality in the world. The goal of the therapy is to reduce symptoms, prevents rehospitalization and increases survivability. Objective. To evaluate the adherence to the European Society of Cardiology for heart failure treatment at H. Adam Malik Medan hospital. Methods. The study was descriptive observational cross sectional design with medical record data of heart failure at $\mathrm{H}$. Adam Malik Hospital, using consecutive sampling method. The adherence of guidelines was assessed by: (1) drug prescribing ("yes" or "no"), and (2) guideline adherence indicator (GAI), both GAI-3 or GAI-5, by calculating the proportion as the number of drugs prescribed by number of drugs indicated to the ESC guidelines. Results. From research, the predominant GAI-3 and GAI-5 were High, which were $54.9 \%$ and $59.5 \%$, respectively. The recommended drug used based on indications were ACE-i / ARB (89.1\%), beta-blockers (83.4\%), MRA (73.6\%), diuretics (93.7\%), and digitalis $(20,8 \%)$. Conclusion. The predominant category in adherence to the ESC heart failure treatment guidelines based on GAI-3 and GAI-5 is High.
\end{abstract}

Keyword: Heart Failure, Guidelines, ESC, GAI

Received 31 December 2019 | Revised 9 January 2020 | Accepted 18 January 2020

*Corresponding author at: Department of Cardiology and Vascular Medicine, University of Sumatera Utara, Medan, Indonesia 


\section{Introduction}

Heart failure is a group of clinical syndromes which is caused by structural or functional heart disorders which disrupt the ability of the ventricle to fill or eject blood [1,2]. The prevalence of heart failure in Indonesia and the world is still high $[3,4]$.

Heart failure therapy must be done according to the suitable treatment to increase the success of treatment, quality of life, and reduce both the mortality and morbidity of the patient $[3,4]$. Appropriate therapy for this condition has been proven effective in reducing the incidence of heart failure [5].

The guideline for heart failure treatment had been released to help doctors in giving the best treatment for the patient The guideline was released by the European Society of Cardiology (ESC) which contain the consensus for pharmacological and non-pharmacological criteria [6]. The ESC's treatment recommendation for heart failure patients are angiotensin converting enzyme inhibitor (ACE-I) or angiotensin receptor blocker (ARB), beta blockers, and mineralcorticoid receptor antagonist (MRA) for heart failure therapy. Diuretics could be used in combination to relieve symptoms and signs of congestion [4].

This study is a continuation from a previous study conducted by Andika Sitepu and Khalis Hamdani during the period of January 2013 - June 2014. The aim of this study is to see whether or not there is a difference in obedience of the ESC guideline on heart failure patients in Adam Malik Central General Hospital, Medan.

\section{Methods}

This is descriptive observational study which was conducted on July - December 2019. This study uses medical record data of 284 patients chronic heart failure with reduced ejection fraction that meets the inclusion and exclusion criteria at the Haji Adam Malik General Hospital Medan from January 2015 - December 2018. The samples were collected by consecutive sampling method from 2015 - 2018 patients medical record until get a total of 284 patients.

Inclusion criteria were: (i) age over 18 years, (ii) outpatient with chronic heart failure, (iii) reduced ejection fraction $\leq 40 \%$. We excluded Patient presenting with: (i) Asthma, (ii) COPD (Chronic Obstruction Pulmonary Disease) acute exacerbation, (iii) symptomatic hypotension (systolic blood pressure < $90 \mathrm{mmHg}$ ), (iv) severe aortic stenosis, (v) severe mitral stenosis, (vi) renal artery stenosis and (vii) hyperkalemia.

The guidelines adherence indicator (GAI) was used to evaluate physician adherence to the ESC guidelines for the treatment of chronic heart failure with reduces ejection fraction ${ }^{6}$. The GAI specified into two different groups. GAI-3 consists of ACE-I or ARB, beta-blocker, and MRA, considering the substantial evidence to improve clinical outcome. The GAI-5, in addition to the 
three pharmacological classes, considered the use of diuretics and digitalis, which predominantly targets improving symptoms. Furthermore, GAI-3 was three categories; these were low adherence ( 0 or $33 \%$ ), moderate adherence (67\%), and high adherence (100\%).In the same way, GAI-5 was three categories; these were low adherence (0-20\%), moderate adherence (40-60\%), and high adherence $(80-100 \%)$.

\section{Results}

Table 1 Patients characteristics

\begin{tabular}{|c|c|c|}
\hline Characteristics & Population $(\mathrm{n}=284)$ & Percentage $(\%)$ \\
\hline \multicolumn{3}{|l|}{ Gender: } \\
\hline Male & 221 & 77,8 \\
\hline Female & 63 & 22,2 \\
\hline \multicolumn{3}{|l|}{ Age : } \\
\hline$<50$ tahun & 91 & 32,0 \\
\hline 50 - 75 tahun & 185 & 65,1 \\
\hline$>75$ tahun & 8 & 2,8 \\
\hline
\end{tabular}

Table 1 show patients' heart failure characteristics that, male tend to develop heart failure than female from 284 patients diagnosed with heart failure. By age, the peak incidence of HCC was in $50-75$ years $(65,1 \%)$. For <50 years, there are 91 patients diagnosed with heart failure $(32,0 \%)$, and $>75$ years, there are 8 patients diagnosed with heart failure $(2,8 \%)$.

Table 2 Pharmacology treatments for heart failure

\begin{tabular}{|c|c|}
\hline Medication & Population $(n=284)$ \\
\hline Captopril & $148(52,1)$ \\
\hline Ramipril & $53(18,7)$ \\
\hline Valsartan & $42(14,8)$ \\
\hline Candensartan & $9(3,2)$ \\
\hline Irbesartan & $1(0,4)$ \\
\hline Bisoprolol & $235(82,7)$ \\
\hline Carvedilol & $2(0,7)$ \\
\hline Spironolakton & $209(73,6)$ \\
\hline
\end{tabular}


Furosemid

Digoxin
$266(93,7)$

$59(20,8)$

Table 2 shows that the prescription rates for ACE-I/ARBs were $89,2 \%$, followed by beta-blockers $(83,4 \%)$, and MRAs $(73,6 \%)$. In addition to the three substance classes, the prescription rates diuretic was the highest $(93,7 \%)$ and the use of digitalis was $20,8 \%$.

Table 3 guideline adherence indicators

\begin{tabular}{lcccc}
\hline & Low, n (\%) & Moderate, n $(\%)$ & High, n (\%) & Median (IQR) \\
\hline GAI-3 & $25(8,8)$ & $103(36,3)$ & $156(54,9)$ & $100 \%(67-100 \%)$ \\
GAI-5 & $4(1,4)$ & $111(39,1)$ & $169(59,5)$ & $80 \%(60-80 \%)$
\end{tabular}

Table 3 shows that the predominant category for both GAI-3 and GAI-5 were high, 156 (54.9\%) and 169 (59.5\%) respectively. Table 3 also shows the median values of both GAI-3 (100\%) and GAI-5 (80\%) were also calculated to determine the overall quality of pharmacology.

\section{Discussion}

From the study, we get that heart failure is more dominant in male than in female. This is similar as the other studies from Sitepu \& Hamdani, Jensen et al., and Savaresa \& Lund $[6,8,9]$. This study also shows that the incidence of heart failure increase corresponding with the increase of age. The result is similar with previous study from Sitepu \& Hamdani, Lee et al., and Riskesdas $[6,10,11]$. Despite that, due to lower life expectancy in Indonesia [10], the average age of patients is younger compared to the other studies.

ESC guidelines recommend neurohormonal antagonist heart failure drugs that must be given to heart failure patients with reduced ejection fractions namely ACE-I/ARB, beta-blockers, and MRA [12]. The prescription rates for ACE-I/ARBs was $89,2 \%$, followed by beta-blockers $(83,4 \%)$, and MRAs $(73,6 \%)$. The result shows improvement of prescription rates for neurohormonal antagonist heart failure treatment from previous study [6]. Diuretics were the most frequently prescribed in this study, with 93,7\%, this finding in line with previous study [6]. Other studies also reported the use of diuretics as the most commonly prescribed drugs [13,14]. In our study, high prescription diuretic drugs may be due to most patients experiencing signs of congestion which is dyspnea.

The adherence to the ESC guidelines was associated with better prognosis, improved clinical outcome, fewer cardiovascular hospitalizations and delayed time to rehospitalization [6]. In our study, we found that the predominant categories of GAI-3 $(54,9 \%)$ and GAI-5 $(59,5 \%)$ were high, similar to the other study $[14,15]$. The adherence of both GAI-3 and GAI-5 based on ESC guidelines has increased from moderate to high compared to previous studies [6]. The median 
values of GAI-3 and GAI-5 were also used to evaluate the pharmacotherapy quality [14]. This results shows a significant improvement of median values of GAI-3 and GAI-5 from previous studies. This might be possible because the distribution of drugs in the Adam Malik General Hospital was sufficient.

\section{Conclusion}

This is the follow-up study from previous study conducted by Sitepu and Hamdani. In our study, the adherence to ESC guidelines for the treatment of heart failure has improved significantly compared to previous study, from moderate to high adherence.

\section{References}

[1] Pazos-López, P., Peteiro-Vázquez, J. Carcía-Campos, A. et al. 2011, The causes, consequences, and treatment of left or right heart failure. Vascular Health and Risk Management, 7(1), 237-254

[2] Wehling, M. ed., 2012, Drug therapy for the elderly, Springer Science \& Business Media.

[3] Riskesdas. 2013 , Jakarta: Badan Penelitian dan Pengembangan Kesehatan Departemen Kesehatan Republik Indonesia, (Penyakit Menular), 103.

[4] Luepker, R.V. 2017, "Epidemiology of Heart Failure," Congestive Heart Failure and Cardiac Transplantation: Clinical, Pathology, Imaging and Molecular Profiles, 93-102.

[5] Giezeman. Maaike. Arne, M. et al. 2017. "Adherence to Guidelines in Patients with Chronic Heart Failure in Primary Health Care." Scandinavian Journal of Primary Health Care 35 (4): 336-43.

[6] Sitepu, A., \& Hamdani, K. 2018, "Adherence to the European Society of Cardiology Guidelines for the Treatment of Chronic Heart Failure," IOP Conference Series: Earth and Environmental Science 125 (1).

[7] Crespo-Leiro, M.G., Segovia-Cubero. J. González-Costello. et al. 2015. Adherence to the ESC heart failure treatment guidelines in Spain: ESC heart failure long-term registry. Revista Española de Cardiología (English Edition), 68(9), pp.785-793.

[8] Jensen, J., Schou, M., Kistorp, C. et al. 2019, Prevalence of heart failure and the diagnostic value of MR-proANP in outpatients with type 2 diabetes. Diabetes, Obesity and Metabolism, 21(3), pp.736-740.

[9] Savarese, G. \& Lund, L.H. 2017, Global public health burden of heart failure. Cardiac failure review, 3(1), p.7. 
[10] Badan Pusat Statistik. 2018, Umur Harapan Hidup Saat Lahir (UUH) Menurut Provinsi, 2010-2018 (Metode Baru).

[11] Lee, J.H., Lim, N.K. Cho, M.C. et al. 2016, Epidemiology of heart failure in Korea: present and future, Korean circulation journal, 46(5), pp.658-664.

[12] Coats, Andrew J.S., Pieske, B, et al. 2016, "2016 ESC Guidelines for the Diagnosis and Treatment of Acute and Chronic Heart Failure: The Task Force for the Diagnosis and Treatment of Acute and Chronic Heart Failure of the European Society of Cardiology (ESC)Developed with the Special Contribution Of." European Heart Journal 37 (27): 2129-2200. https://doi.org/10.1093/eurheartj/ehw128.

[13] Komajda, M., Cowie, M.R. Tavazzi, L. et al. 2017, Physicians' guideline adherence is associated with better prognosis in outpatients with heart failure with reduced ejection fraction: the QUALIFY international registry. European journal of heart failure, 19(11), pp.1414-1423.

[14] Störk, S., Hense, H.W. Zentgraf, C. et al. 2008, Pharmacotherapy according to treatment guidelines is associated with lower mortality in a community-based sample of patients with chronic heart failure: A prospective cohort study. European Journal of Heart Failure 10: $1236-1245$.

[15] Komajda, M., Lapuerta, P. Hermans, N. et al. 2005, "Adherence to Guidelines Is a Predictor of Outcome in Chronic Heart Failure: The MAHLER Survey.” European Heart Journal 26 (16): 1653-59. 